\title{
PENTINGNYA VARIASI HIDANGAN BREAKFST DALAM MENINGKATKAN KEPUASAN TAMU HORISON ULTIMA MALANG
}

\author{
Virgiawan Ilham Pratomo ${ }^{1}$ \\ Estikowati $^{2}$ \\ Program Diploma Kepariwisataan Universitas Merdeka Malang \\ Jl. Bandung No. 1 Malang
}

Korespodensi dengan Penulis:

Estikowati: Telp : 081216495703

E-mail : estiwin97@gmail.com

\begin{abstract}
The goal of this research is : 1. Increasing the satisfaction of visitors who come and stay at Hotel Horison Ultima by improving the breakfast quality which are provided by the hotel, 2. Knowing the provision of dishes which later can increase visitors' satisfaction. Knowing the description of the hotel breakfast menu variations provided by Hotel Horison Ultima (Main Dish, Side Dish, Tematic Dish). Understanding the condition of the food such as freshness, completeness, preparation and design in color management and hygiene must be considered because it will be closely related to what visitors think. Dish variation can also be a part in term of improving visitors' satisfaction. By satisfying visitors' needs, hotel can also increase competitive advantage. Visitors who are satisfied by the products and services are likely to buy back the products and reuse services.
\end{abstract}

Keyword: Breakfast variations, visitor satisfaction, dish Conditions

Salah satu pekerjaan atau kegiatan yang bergerak di bidang jasa yaitu hotel. Hotel adalah salah satu jenis akomodasi yang mempergunakan sebagian atau keseluruhan bagian untuk jasa pelayanan penginapan, penyedia makanan dan minuman serta jasa lainnya yang dikelola secara komersil. Selain itu, hotel juga menyediakan berbagai macam fasilitas di dalamnya, baik indoor maupun outdoor. Dan peranan penyedia makanan adalah salah satu bagian terpenting di bidang jasa hotel, suatu variasi hidangan yang menarik dan sesuai untuk pengunjung hotel yang akan tinggal atau menginap di hotel.

Breakfast adalah salah satu produk yang ditawarkan hotel untuk memudahkan pengunjung yang menginap dalam memenuhi 
kebutuhan untuk makan. Dengan adanya pelaksanaan breakfast di hotel, pengunjung akan lebih mudah dalam memenuhi kebutuhan pangan. Begitu juga dengan variasi hidangan di hotel yang sebaiknya lebih diperhatikan oleh pihak hotel, karena dengan danya konflik mengenai variasi hidangan akan sangat merugikan hotel dan mengbakibatkan pengunjung hotel pun berkurang karena kecewa dengan variasi hidangan breakfast yang ada di hotel. Berbagai variasi hidangan yang disedikakan oleh hotel meliputi makan utama, makanan pendamping, makanan tematik atau tradisional dan makanan lainnya.

Variasi dari suatu hidangan ketika Breakfast di hotel sangatlah penting, karena apabila variasi menu terhadap tamu kurang menarik akan membuat tamu hotel kecewa dengan pelayanan yang disediakan di hotel. Pentingnya variasi hidangan breakfast juga dapat berupaya meningkatkan kepuasan dari tamu hotel karena pelayanan di hotel yang diberikan dan disediakan untuk pengunjung harus baik dan memuaskan, jika peranan variasi breakfast tidak diperhatikan baik-baik akan mempengaruhi terhadap kepuasan tamu di hotel.

Segala bentuk menu hidangan breakfast yang ada yaitu kondisi makanan, ragam warna, desain hidangan, serta kebersihan hidangan harus diperhatikan karena akan dirasakan atau didapat pengunjung secara langsung. Pelanggan memang harus dipuaskan, sebab jika tidak puas akan meninggalkan perusahaan dan menjadi pelanggan pesaing.

\section{METODE}

Teknik analisis yang digunakan dalam mengalisa data adalah teknik analisa deskriptif kualitatif, yaitu suatu teknik yang menggambarkan dan menguraikan secara sistematis data yang di dapat selama penelitian sehinggga nantinya bisa di tarik suatu kesimpulan. Sumber data yang digunakan yaitu data primer dan data sekunder. Data Primer adalah data yang di peroleh secara langsung dari perusahaan yang menjadi tempat penelitian di Hotel HorisonUltima Malang, misalnya fasilitas hotel, struktur organisasi, dan sejarah hotel. Data sekunder adalah data yang diperoleh dari luar objek penelitian misalnya melalui majalah 
atau literatur yang berkaitan dengan masalah yang dibahas. Teknik pengumpulan data yang digunakan meliputi observasi dankuesioner.

\section{HASIL dan PEMBAHASAN}

Breakfastmerupakansalahsatufac toruntukmenunjang kepuasan tamu yang menginap di hotel.Hasilpengamatandari staff kitchen dan pastry Hotel HorisonUltima Malang dengan data penataan hidangan yang kurang bervariasi, peletakan hidangan yang mirip, dan kurang adanya ketertarikan warna pada penyusunan hidangan.

Umumnya penelitian mengenai kepuasan tamu dilakukan dengan penelitian survai, baik melalui pos, telepon, maupun wawancara langsung. Perusahaan akan memperoleh tanggapan dan umpan balik secara langsung dari pelanggan dan juga memberikan tanda (signal) positif bahwa perusahaan menaruh perhatian terhadap para pelanggannya.

Dengan adanya upaya-upaya yang dilakukan oleh pihak Hotel Horison Ultima diharapkan dapat mengurangi keluhan yang didapat dari pengunjung yang datang ke hotel serta dapat meningkatkan kenyamanan dan kepuasan pengunjung yang datang dan menginap di hotel.

Tabel 1. Tentang PenerapanVariasi Hidangan Breakfast Hotel Horison Ultima Malang

\begin{tabular}{|c|c|c|c|c|c|}
\hline \multirow{3}{*}{ No } & \multirow{3}{*}{ Pernyataan } & \multicolumn{4}{|c|}{ Penilaian } \\
\hline & & \multicolumn{2}{|c|}{ Ya } & \multicolumn{2}{|c|}{ Tidak } \\
\hline & & $\mathrm{F}$ & $\%$ & $\mathrm{~F}$ & $\%$ \\
\hline 1. & Hidangan Terlihat baru & 6 & 60 & 4 & 40 \\
\hline 2. & Warna hidangan menarik & 4 & 40 & 6 & 60 \\
\hline 3. & Hidangan berbeda dengan hari sebelumnya & 6 & 60 & 4 & 40 \\
\hline 4. & $\begin{array}{l}\text { Pengecekan variasi dilakukan secara rutin } \\
\text { warna, jenis hidangan, dan keteraturan) }\end{array}$ & 8 & 80 & 2 & 20 \\
\hline \multirow[t]{3}{*}{5.} & $\begin{array}{l}\text { Penyusunan hidangan dilakukan secara baik } \\
\text { dan benar }\end{array}$ & 6 & 60 & 4 & 40 \\
\hline & Total & 30 & $240 \%$ & 20 & $220 \%$ \\
\hline & Rata-rata & & $48 \%$ & & $42 \%$ \\
\hline
\end{tabular}

Sumber : Staff kitchen dan Pastry 
Jumlah yang diteliti : 10 orang

Ya $=$ Dilakukan, Tidak $=$ Tidak Dilakukan

Untuk mengetahui jumlah yang terlihat ditabel diatas dipergunakan rumus sebagai berikut :

$$
\sum=\mathrm{f} / \mathrm{n} \times 100 \%
$$

$\sum=$ Jumlah dari hasil kuisioner, menunjukan jumlah dalam prosentasi.

$\mathrm{f}=$ Frekuensi jawaban responden untuk masing - masing jawaban.

$\mathrm{n}=$ Jumlah responden

Sedangkan untuk mencari rata - rata yang terlihat di tabel diatas dipergunakan rumus sebagai berikut :

Rumus rata-rata $=\mathrm{A} / \mathrm{N}$

\section{Penjelasan:}

1. Hidangan Terlihat baru $6=60 \%$ responden menyatakan "ya" dan $4=40 \%$ responden menyatakan "tidak", dapat dikatakan bahwa hidangan yang disajikan terlihat baru.

2. Warna hidangan menarik $4=40 \%$ responden menyatakan "ya" dan $6=60 \%$ responden menyatakan "tidak", dapat dikatakan bahwa ada banyak hidangan yang memiliki warna kurang menarik.

3. Hidangan berbeda dengan hari sebelumnya6 $=60 \%$ responden menyatakan "ya" dan $4=40 \%$ responden menyatakan "tidak", dapat dikatakan bahwa hidangan breakfast yg disajkan berbeda dengan hari sebelumnya.

4. Pengecekan variasi dilakukan secara rutin warna, jenis hidangan, dan keteraturan) $24=80 \%$ responden menyatakan "ya" dan $6=20 \%$ menyatakan "tidak", dapat dikatakan bahwapengecekan rutin dilaksanakan.

5. Penyusunan hidangan dilakukan secara baik dan benar $6=60 \%$ responden menyatakan "ya" dan 4=40\% responden menyatakan "tidak", dapat dikatakan bahwa hidangyang sudah disusun secara benar. 
Tabel 2. Tentang Kepuasan Tamu yang Menginap

\begin{tabular}{|c|c|c|c|c|c|}
\hline \multirow{3}{*}{ No } & \multirow{3}{*}{ Pernyataan } & \multicolumn{4}{|c|}{ Penilaian } \\
\hline & & \multicolumn{2}{|c|}{$\mathrm{Ya}$} & \multicolumn{2}{|c|}{ Tidak } \\
\hline & & $\mathrm{f}$ & $\%$ & $\mathrm{f}$ & $\%$ \\
\hline 1 & $\begin{array}{l}\text { Produk makanan yang dijual terlihat } \\
\text { menarik }\end{array}$ & 15 & 50 & 15 & 50 \\
\hline 2 & $\begin{array}{l}\text { Makanan yang disajikan sesuai dengan, } \\
\text { harga yang dibayarkan }\end{array}$ & 12 & 40 & 18 & 60 \\
\hline 3 & Rasa masakan memenuhi selera & 12 & 40 & 18 & 60 \\
\hline 4 & Porsi makanan sesuai standar & 12 & 40 & 18 & 60 \\
\hline \multirow[t]{3}{*}{5} & $\begin{array}{l}\text { Temperatur makanan saat disajikan sesuai } \\
\text { dengan jenis masakan }\end{array}$ & 15 & 50 & 15 & 50 \\
\hline & Total & 66 & $220 \%$ & 84 & $280 \%$ \\
\hline & Rata-rata & & $44 \%$ & & $56 \%$ \\
\hline
\end{tabular}

Sumber : Tamu yang menginapdi Hotel Horison Ultima Malang

Jumlah yang diteliti : 30 orang(acuan penarikan sampel dengan teori Roscoe(1975) yang dikutip Uma Sekaran(2006))

Ya $=$ Puas, Tidak $=$ Tidak Puas

Untuk mengetahui jumlah yang terlihat ditabel diatas dipergunakan rumus sebagai berikut :

$$
\sum=\mathrm{f} / \mathrm{n} \times 100 \%
$$

$\sum=$ Jumlah dari hasil kuisioner, menunjukan jumlah dalam prosentasi.

$\mathrm{f}=$ Frekuensi jawaban responden untuk masing - masing jawaban.

$\mathrm{n}=$ Jumlah responden

Sedangkan untuk mencari rata - rata yang terlihat di tabel diatas dipergunakan rumus sebagai berikut :

$$
\text { Rumus rata-rata }=\mathrm{A} / \mathrm{N}
$$

Penjelasan :

1. Produk makanan yang dijual terlihat menarik $15=50 \%$ responden menyatakan "ya dan $15=50 \%$ responden menyatakan "tidak", dapat dikatakan bahwa produk makanan belum terlihat menarik(standar). 
2. Makanan yang disajikan sesuai dengan, harga yang dibayarkan $12=40 \%$ responden menyatakan "ya" dan $18=60 \%$ responden menyatakan "tidak", dapat dikatakan bahwa makanan yang ada tidak sesuai dengan harga yang dibayarkan.

2. Rasa masakan memenuhi selera $12=40 \%$ responden menyatakan "ya" dan $18=$ $60 \%$ responden menyatakan "tidak", dapat dikatakan bahwa rasa masakan belum sepenuhnya memenuhi selera tamu.

3. Porsi makanan sesuai standard $12=40 \%$ responden menyatakan "ya" dan $18=60 \%$ responden menyatakan tidak, dapat dikatakan bahwa porsi tidak sesuai dengan standard

4. Temperatur makanan saat disajikan sesuai dengan jenis masakan $15=50 \%$ responden menyatakan "ya" dan $15=50 \%$ responden menyatakan "tidak", dapat dikatakan bahwa temperatur makanan saat disajikan masih perlu diperhatikan

Kurangnya variasi hidangan breakfast, akan menimbulkan kurangnya keterterikan tamu akan suatu hidangan yang disajikan di hotel tersebut. Jika tamu merasa kurang tertarik maka tamu juga akan meras kurang dipuaskan. Alternatif pemecahan masalah yang dapat dilakukan diantaranya: (1)melakukan pengengecekan ketika pembuatan menu untuk breakfast. Keuntunganya hidangan akan terus dipantau dan memaksimalkan kualitas hidangan, kekurangannya akan membuang lebih banyak waktu dalam proses pengerjaan, (2) melakukan training/pelatihan terhadap staff(cook). Keuntungan staff akan mendapat masukan baru dan bisa lebih mandiri dan kreatif. Kekurangannya jika terjadi kelalaian dalam over handle job shift maka kemungkinan menu yang akan dikeluarkan bisa mirip dengan hidangan sebelumnya, (3) menerapkan rotasi menu. Keuntungan Menu hidangan pasti berubah setiap harinya, Kekurangannya apabila ketidaktersediaan barang dalam chiller maupun freezer maka tidak akan bisa mengikuti rotasi menu.

Sesuai dengan akibat masalah dan langkah pemecahan masalah yang sudah disebutkan, maka penulis mengharapkan adanya kesadaran dari karyawan kitchen dan pastry dengan peningkatan kreatifitas dalampenerapan variasi hidangan breakfast di Hotel HorisonUltima Malang. 


\section{KESIMPULAN}

Dilihat dari sumberdaya manusia yang berkualitas di area Kitchen dan pastry Hotel Horison Ultima Malang ternyata banyak hal yang harus diperbaiki karena banyak karyawan yang kurang memerhatikan pentingnya variasi hidangan. Berdasarkan data yang diperoleh beserta analisa terhadap data kuisioner diperoleh kesimpulan yaitu 52\% staff kitchen dan pastry belum maksimal dalam upaya penerapan variasi hidangan breakfat. Sedangkan yang 68\% responden dari tamu yang menginap belum belum mendapatkan kepuasaan sesuai dengan yang mereka harapkan dari hidangan breakfast yang ada.

\section{DAFTAR RUJUKAN}

Anonimous. 2011. Faktor yang Mempengaruhi Kepuasan Konsumen. ((Online). Skripsimanajemen-blogspot.co.id)

Irawan, Juwandi Hendi. 2004. Kepuasan Pelayanan Jasa. Jakarta : Erlangga.

Sheraton Media Hotel dan Towers. 2009. ((Online). http://einternalmagz.ilmuperhotelan.blogspot.co.id). 